\title{
Personified Behavioural Demand Response Model for the Reduction of Peak Time Energy Consumption Coincidence of Domestic Sector with the Utility
}

\author{
SWATHI $\mathrm{G}^{1 *}$, SUDHA RANI DONEPUDI ${ }^{2}$, K. RAMASH KUMAR ${ }^{3}$ \\ 'Department of Electrical and Electronics Engineering, Koneru Lakshmaiah Education \\ Foundation, Vaddeswaram, Andhra Pradesh, INDIA. \\ ${ }^{2}$ Department of Electrical and Electronics Engineering, Sri Vasavi Engineering College, \\ Andhra Pradesh, INDIA. \\ ${ }^{3}$ Department of Electrical and Electronics Engineering, Dr.N.G.P. Institute of \\ Technology, Coimbatore-48, Tamilnadu, INDIA.
}

\begin{abstract}
Curtailment of discrete customer's demand coincidence with utility demand during peak time ends up in good benefits to the utility at different levels as this coincidence is very expensive due to additional requirement of demand. Though few Demand Response(DR) programs are working towards this peak time energy coincidence reduction, they are not that successful due to either requirements of technological installations near customer premises or penalising the customer or lack of encouraging the customer to achieve the reduction. This work proposes a Personified Behavioural Demand Response (P-BDR) model especially for residential customers as they are good contributors of peak time demand. Rather than coaxing or compelling the customer, the proposed model relies on customer's motivation regarding the peak time energy conservation, setting targets based on their monthly contribution to utility peak time demand and measuring their achievements through feedback models. P-BDR model comprises of Target/Goal setting model based on forecasted data and feedback model based on real time data of individual customer. This model is observed on synthetic smart meter data of 20 discrete domestic customers. For the better application of the model, customers are clustered into 4 categories using K-Means Machine learning algorithm. The model sets an individual target of 5\%-15\% energy consumption reduction during utility peak time based on the customer classification. The model achieves an overall consumption reduction of $14.9 \%$ during peak time with the proposed model.
\end{abstract}

Keywords: Utility Peak time demand coincidence, Behavioural Demand Response strategy, individual domestic customer, K-means algorithm, Machine learning, Peak time energy consumption limit.

Received: May 25, 2021. Revised: November 28, 2021. Accepted: December 21, 2021. Published: December 31, 2021.

\section{Introduction}

Variation of electricity demand with the time of the day results in peak and off-peak loads [1], thus stressing the utility to maintain peak demand by investing in additional generation plants and equipment. Wrong investment either excessive or insufficient by the utility in reaching the peak demand, results in either wastage of the asset or power shortage problems that causes discomfort to both suppliers and consumers. Also, these peak demand hours which are usually met by fossil fuel sources like coal, oil etc., are more prone to high carbon emissions than off-peak hours [2]. Customers can reduce electricity production, distribution and supply cost thereby total electricity charge by reducing their demand coincidence with the utility peak demand. Peak time energy conservation helps to greatly reduce network loading and hence 
reduces technical, T\&D losses at utility level especially during peak hours. Thus, to ensure the reliability and security of the power systems, peak time energy conservation is crucial. An action at the customer side that encourages peak time energy conservation is Demand Response (DR). DR focuses on the load shifting during peak hours to off-peak hours by the customers to reduce peak load demand which releases the utility from the burden of generation margins. The most fascinating part of the DR is that the customers can control the prices they pay for their consumption especially during time varying prices. Broad classification of Demand Response programs is shown in figure 1.
- Incentive based DR programs are those in which the utility controls the consumption of the customers during emergency events by incentivising the customer and penalising them if they fail to respond. They include programs like Capacity Market Programs (CMP), Direct Load Control (DLC), Emergency Demand Response Programs (EDRP), Interruptible/Curtailable (I/C) service, Demand Bidding/buyback (DB), and Ancillary Services Market Programs (ASMP).

- Price-based DR programs are those in which the consumers change their consumption patterns based on the time-

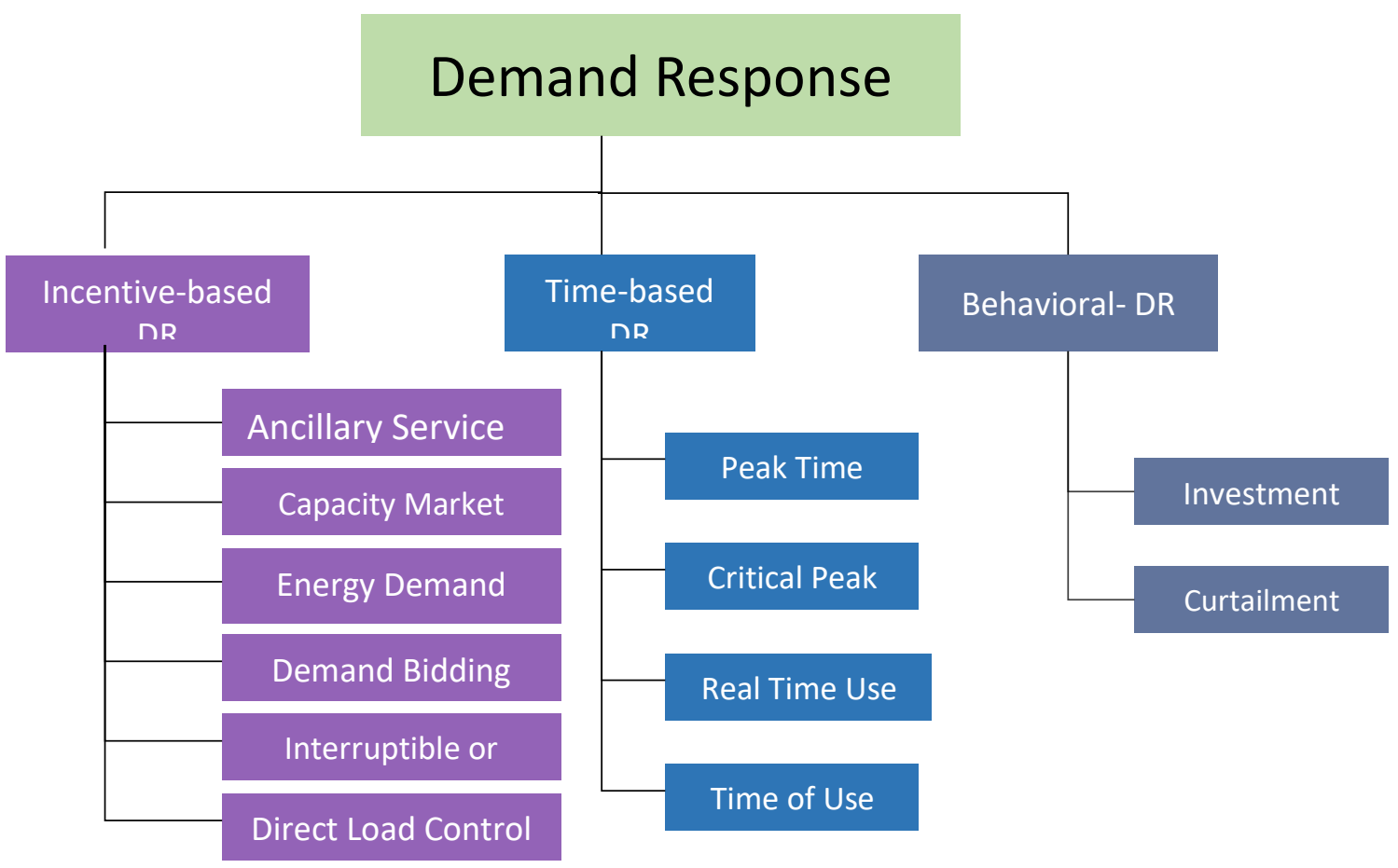

Fig 1: Types of Demand Response

varying electricity prices to get benefits by shifting their loads to off-peak hours. They include Time-of-Use (TOU) rates, RealTime Pricing (RTP) and Critical Peak Pricing (CPP). [3,4] explains these DR programs in detail.

- On the other hand, Behavioural Demand Response (BDR) is a demand response strategy that has a good potential of peak time energy conversation through 
behavioural change in consumption style of

the customer specifically during peak hours but has gained less popularity due to the difficulty of quantifying its benefits like other DR programs. BDR educates and encourages the consumers to change their consumption patterns during peak hours through motivation, targets and feedbacks based on social comparisons. BDR neither offers financial

incentives to consumers for their consumption reduction nor requires technology installations near consumer premises to change their consumption. Investment BDR, that requires financial investment and curtailment BDR that needs nominal or no financial investment are two types of BDR programs.

\section{Related work}

Based on the literature review on human behaviour change in achieving the energy consumption, it was found that a reduction of up to $20 \%$ on electricity consumption [5] and peak time energy conservation between $15 \%$ $21 \%$ [6] can be achieved through different interventions of human behaviour change. India has been chosen as a case study in the present work as India is a vast country with huge population and is the world's third largest producer and consumer of electricity with the installed capacity of $374 \mathrm{GW}$ [7].As per the National Electricity Plan prepared by the Central Electricity Authority(CEA), it is estimated that electricity demand would rise to $900 \mathrm{GW}$ and peak demand would rise to 690GW by 2030 [8] .Besides this, with the emerging challenges like frequent power cuts, poor power quality, Very high T\&D losses, high co2 emissions, India's power system needs to grow at a higher rate and needs smarter systems to overcome above challenges. One such solution that can mitigate above mentioned challenges is Demand Response(DR).

According to Siddiqui, M.Z in [9], Demand response is in its budding stages in India due to many reasons like lack of implementation framework, trust, management etc. But there is a great potential for DR in India. Based on the integrated analysis by both NMEEE and PwC, regarding market potentiality of DR and DSM activities amongst different demand side sectors of India, it is clear that the residential sector has the highest potential of energy savings and peak demand reduction [10]. Today, residential consumption accounts for $24 \%$ of electricity produced in India, of which $75 \%$ is used for lighting and cooling [11]. Faruqui, A.et al based on a study in the USA suggests that DR can achieve more in the residential sector with a possibility of $43 \%$ peak demand reduction than $13 \%$ for both commercial and industrial sectors together [12]. There is a great possibility of energy and peak time energy conservation at residential level just by adapting simple behaviour change in their electricity consumption patterns. It was found in [13] that 57 houses out of 105 houses lessened their electricity consumption just by switching off the lights in unoccupied rooms. According to [14], in developing countries like India with huge population, where technology may not reach to everyone, Behavioural Demand Response (BDR) out of all Demand Response programs, can be easily carried out at residential level with relatively less or no cost and short achievement duration. Motivation for the customer and the customer awareness are the primary factors to boost a DR program [15]. Table 1 has been done obtained based on [16] which shows that BDR has a good capability of demand reduction with less capital cost and less time to achieve amongst all DR programs.

Table 1: Comparison of different DR programs

\begin{tabular}{|l|l|l|l|}
\hline Strategy & $\begin{array}{l}\text { Capital } \\
\text { cost }\end{array}$ & $\begin{array}{l}\text { Time to } \\
\text { achieve }\end{array}$ & $\begin{array}{l}\text { \% of } \\
\text { deman } \\
\text { d } \\
\text { reducti } \\
\text { on }\end{array}$ \\
\hline BDR & $\begin{array}{l}\text { Minimu } \\
\text { m or no } \\
\text { cost }\end{array}$ & $\begin{array}{l}\text { Relative } \\
\text { ly short } \\
\text { periods }\end{array}$ & $0.5-22$ \\
\hline $\begin{array}{l}\text { Price based } \\
\text { DR(TVR) }\end{array}$ & $\begin{array}{l}\text { Low } \\
\text { cost }\end{array}$ & $\begin{array}{l}\text { Short } \\
\text { periods }\end{array}$ & $1-30$ \\
\hline $\begin{array}{l}\text { Incentive } \\
\text { based } \\
\text { DR(Technolo } \\
\text { gy) }\end{array}$ & $\begin{array}{l}\text { Maximu } \\
\text { m of all }\end{array}$ & $\begin{array}{l}\text { Lengthy } \\
\text { time } \\
\text { periods }\end{array}$ & $11-38$ \\
\hline
\end{tabular}




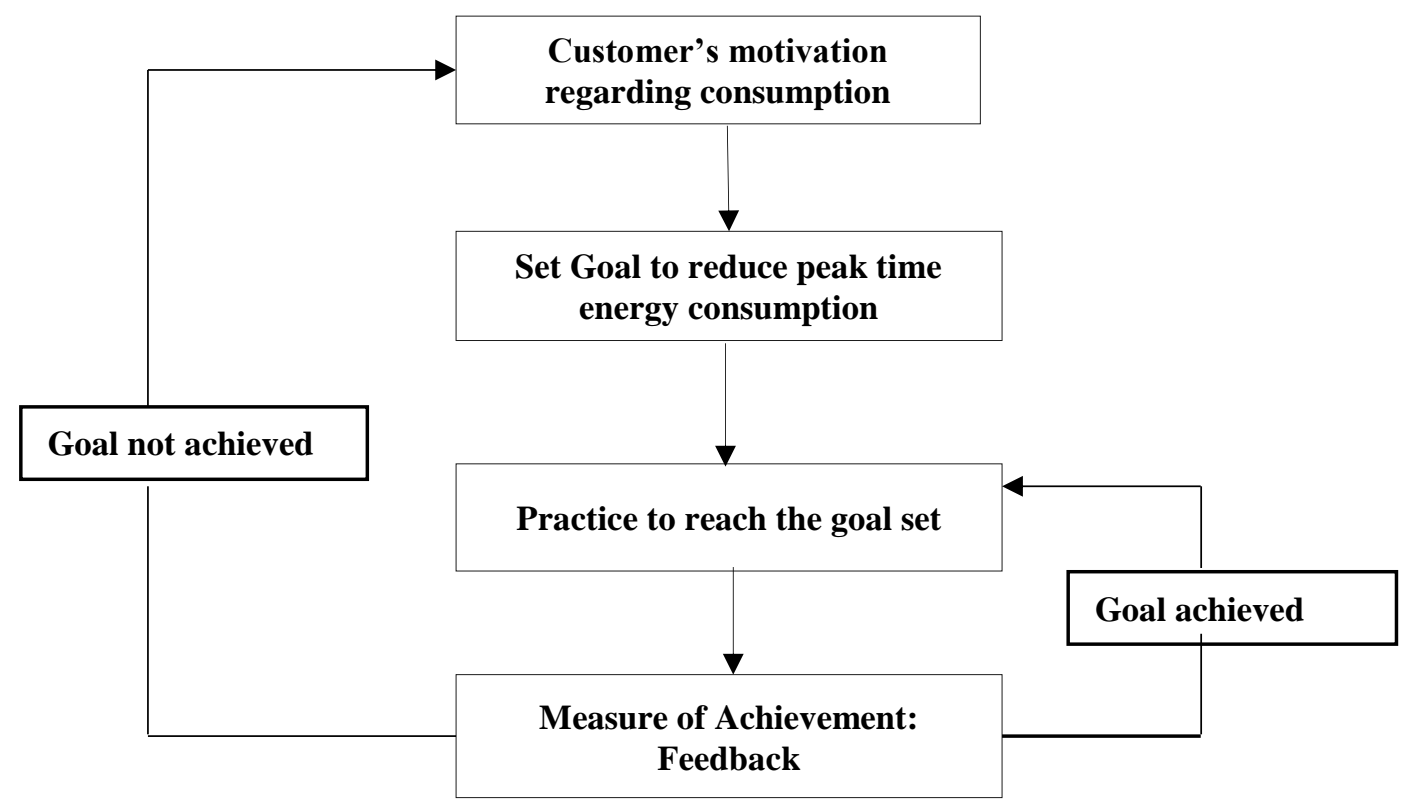

Fig 2: Systematic flow of BDR

\subsection{Research Highlights}

- The present work focuses on the study and development of personified BDR model as a peak time energy conservation strategy in the developing world focusing particularly on Residential sector of India.

- The primary contribution of this paper is a proposed individual target and feedback model as part of BDR to reduce the domestic customer's demand coincident with the system's peak energy through a case study.

- Based on the individual customer's forecasted consumption data, customers are classified into different segments based on Machine learning algorithm K-means.

- This model helps to motivate every domestic customer by setting monthly targets in the form of peak time consumption limit.

Workflow of BDR with different stages is presented in section 3. Proposed model for individual goal/target setting using k-means clustering and individual feedback model and their impact on peak-time energy conservation is discussed in this section. Section 4 concludes the work with possible policy implications.

\section{Behavioral Demand Response model}

BDR works through motivation, targets and feedbacks based on social comparisons to the customers to encourage them to change their consumption patterns. BDR neither offers financial incentives to the consumers for their consumption reduction nor requires technology installations near consumer premises to change their consumption when used with different time varying pricing schemes like TOU helps in greater achievement at residential level. BDR has not gained much popularity and support like

other DR programs as its outcomes cannot be measured immediately like Time of Use. It is at most important to interact with and educate a customer through personal motivations and informative feedbacks about their consumption to achieve sustainability and energy conservation rather than pressurizing or luring the customer with some constraints. Many programs that were aimed to reduce energy use are unproductive due to their lack of inspiring and interacting with the customer effectively with meaningful energy information. This present proposed work targets individuals' personal motivations and goals in combination with weekly indirect 
feedback to decrease electricity consumption esp. during peak time for peak time energy conservation. Steps followed in implementing BDR at household level is represented in figure 2 .

Different steps followed in BDR are as follows:

- Motivate a customer through awareness and education:

- a reduction of up to $20 \%$ can be achieved on electricity consumption just by customer's electricity usage behaviour change through different interventions.

- Goal setting to aspire a person: Availability of information to customer regarding their energy consumption alone does not lead to energy saving achievement. A system that analyses and turns this information into meaningful and specific action in the form of goal/target that helps the customer in load curtailment/shifting to achieve the energy savings will be at most useful. It was found in [18] that energy consumption reduction between $19.5 \%$ and $21.9 \%$ can be achieved through goal setting to the customers.

- Practice to reach the goal: A responsible customer starts practicing energy saving behaviours such as turning off the electrical devices that are not in use, replacing the inefficient devices with efficient ones, shifting the load during peak hours to off-peak hours etc. to achieve the set goal/target.

- Measure of goal achievement: Feedback: Feedback is a factor that helps customers to measure their closeness to goal achievement and thus encourages them in reaching their goal. Wastage of energy consumption at domestic sector can be reduced at greater level by making their consumption data available to the customers through feedbacks. Author in [19] found that energy saving goal along with feedback to the customers
Customer's motivation is a key initiative in BDR at residential level. Different customers get motivated to reduce or change their energy use through different aspects like social responsibility and comparisons, economic aspects, customer education through campaigns etc. In a study conducted in UK [17], it was found that

resulted in higher savings when compared to the target alone.

Feedbacks to customers are of 2 types:

- Direct feedback that relies on smart meters and in-home displays,

- Indirect feedback that relies on personal goal setting, feedback, enhanced billing etc.

\subsection{Proposed Target/Goal setting model:}

A model has been proposed for individual customer's goal setting with a focus of encouraging the customer to shift or to redistribute the peak time consumption to offpeak times of the day, in order to reduce customer's demand coincident with system peak demand, thereby improving overall system efficiency and producing a net saving for the economy. This proposed model sets a limit a month ahead on the peak-time energy consumption (peak time consumption limit) for each customer based on the individual forecasted data in the form of goal/target. Individual customer's smart meter data is forecasted on half an hour granularity a month ahead. Machine Learning Algorithm Support Vector Regression (SVR) is used to forecast the data which is not discussed much in this work. This half-an-hour granular forecasted data is aggregated during peak and off-peak hours to obtain peak hour and off-peak hour consumption of individual customers. As the main focus of the work is peak-time energy consumption reduction in India at the residential level, peak time in this study is referred as shown in table 2 based on All India Load Curve [20] by considering March-June as summer and remaining months as nonsummer in India. 
Table 2: Proposed peak times in India based on All India Load Curve

\begin{tabular}{|l|l|}
\hline Season & On-peak timings \\
\hline Non-summer & 7am-10am 7\& 6pm-9pm \\
\hline Summer & 7am-10am \& 2pm-9pm \\
\hline
\end{tabular}

As India is working towards smart meter data installations at residential level, generous smart meter data is not available. Hence synthetic smart meter data has been created for 20 houses that consists of half-an- hour consumed data for all days in a year, which on aggregation gives daily, monthly and yearly data at individual level. In this model, goal is set to each customer based on 2 estimated factors as shown in equations (1), (2).In equation (1), estimated individual monthly onpeak $\%$ gives the ratio of forecasted individual customer's consumption during peak hours to his/her forecasted total monthly consumption. On the other hand, estimated utility level monthly on-peak $\%$ of each house in equation (2) gives the ratio of his/her contribution to the total peak time consumption of all the customer's fed by the utility based on forecasted data. If the set target is too high, it may not be possible for all the customers to suddenly change their lifestyle and shift the loads during peak hours. For example, a customer with monthly consumption of $280 \mathrm{kWh}$ and peak time consumption of $140 \mathrm{kWh}$ cannot be imposed with same target unit reduction as that of customer with $1011 \mathrm{kWh}$ monthly consumption and $409 \mathrm{kWh}$ peak time consumption. Also, a common target to all the customers may lead to externality problem. Hence the target needs to be set based on individual customer's total monthly consumption and monthly peak time consumption so that it does neither impose too much reductions which may discourage the customer nor too ease which further encourages peak time consumption. 50th percentile of estimated individual monthly onpeak $\%$ and estimated utility level monthly onpeak $\%$ of all houses is considered as baseline energy consumption, where 50th percentile is the point in the data where $50 \%$ of the data falls below that point, and $50 \%$ falls above it. Comparative analysis of each individual customer's consumption with the baseline consumption is performed and customers are classified into 4 groups based on the criteria shown in figure 3 considering estimated individual and utility monthly on-peak $\%$. Goal/target regarding peak time consumption reduction considered for each consumer category is also shown in figure 3 .

Individual monthly on-peak $\%$ of each house $=\frac{\text { Individual monthly total peak time consumption }}{\text { Individual monthly total electricity consumption }}$

Utility-level monthly on-peak $\%$ of each house $=\frac{\text { Individual mothly total peak-time consumption }}{\text { Total monthly peak-time consumption fed by the utility }}$ 


\section{CRITICAL}

Estimated individual monthly on-peak $\%>50^{\text {th }}$ percentile

Estimated utility level monthly on-peak $\%>50^{\text {th }}$ percentile

Target of $15 \%$ peak time consumption reduction

\section{HIGH}

Estimated individual monthly

on-peak $\%>50^{\text {th }}$ percentile

Estimated utility level monthly on-peak $\%<50^{\text {th }}$ percentile

Target of $10 \%$ peak time consumption reduction

\section{$\mathrm{HIGH}$}

Estimated individual monthly on-peak $\%<50^{\text {th }}$ percentile

Estimated utility level monthly on-peak $\%>50^{\text {th }}$ percentile

Target of $10 \%$ peak time consumption reduction

\section{MODERATE \\ Estimated individual monthly on-peak $\%<50^{\text {th }}$ percentile \\ Estimated utility level monthly on-peak $\%<50^{\text {th }}$ percentile \\ Target of 5\% peak time consumption reduction}

Fig 3: Criteria for individual Goal/target setting regarding peak time consumption reduction

Machine Learning algorithm, K-means clustering has been used to segment the customers based on the criteria as shown in figure 3. K-means is one of the simplest unsupervised learning algorithms that is discussed in detail in $[21,22]$.

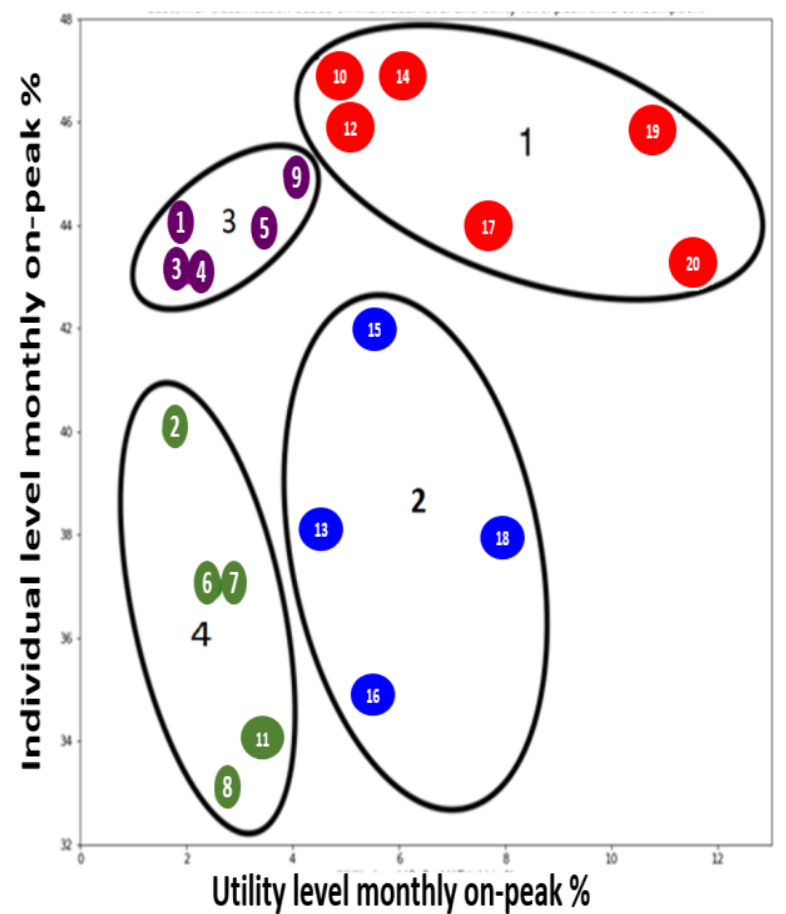

Fig 4: Classification of customers using Kmeans
Figure 4 shows the classification of 20 customers into different clusters using kmeans. Thus, customers in cluster 1 are considered as 'critical' customers as their contribution to the utility's peak time consumption is more than $50 \%$ as well as individual peak time consumption to their total consumption is very high. Hence a consumption reduction of $15 \%$ during peak time is proposed. Customers in cluster 2 are those who contributes to more than $50 \%$ of the utility's peak time consumption even though their individual peak time consumption is less than $50 \%$ of their total consumption. Whereas cluster 3 are those whose peak time consumption is above $50 \%$ of their total monthly consumption but contributes less at utility level. Hence cluster 2 and cluster 3 customers are considered as 'high' and hence a reduction of $10 \%$ is proposed for them. Cluster 4 customers are considered 'moderate' and hence $5 \%$ reduction is proposed.

Based on the above proposed model, table 3 shows estimated individual monthly on-peak $\%$ from equation (1), estimated utility level monthly on-peak \% from equation (2) and target /goal set for each customer based on criteria shown in figure (3), figure (4) for a summer month-May. 
Table 3: Individual Target set values based on forecasted consumption values for all the customers

\begin{tabular}{|c|c|c|c|c|c|c|c|c|c|}
\hline H.no & $\begin{array}{l}\text { Forecasted } \\
\text { monthly } \\
\text { total } \\
\text { consumption } \\
(\mathrm{kWh})\end{array}$ & $\begin{array}{l}\text { Estimated } \\
\text { monthly } \\
\text { total On- } \\
\text { peak } \\
\text { consumption } \\
\text { (kWh) }\end{array}$ & $\begin{array}{l}\text { Estimated } \\
\text { monthly } \\
\text { total off- } \\
\text { peak } \\
\text { consumption } \\
(\mathbf{k W h})\end{array}$ & $\begin{array}{l}\text { Estimated } \\
\text { individual } \\
\text { monthly } \\
\text { on-peak } \\
\%\end{array}$ & $\begin{array}{l}\text { Estimated } \\
\text { utility } \\
\text { level } \\
\text { monthly } \\
\text { on-peak } \\
\%\end{array}$ & $\begin{array}{l}\text { Target: } \\
\text { peak-time } \\
\text { energy } \\
\text { consumption } \\
\text { reduction } \\
\text { units }(k W h)\end{array}$ & $\begin{array}{l}\text { Peak time } \\
\text { consumption } \\
\operatorname{limit}_{\left(P_{L}\right)} \\
(\mathbf{k W h})\end{array}$ & $\begin{array}{l}\text { Estimated } \\
\text { individual } \\
\text { monthly } \\
\text { on-peak } \\
\% \text { after } \\
\text { reduction }\end{array}$ & $\begin{array}{l}\text { Estimated } \\
\text { utility } \\
\text { level } \\
\text { monthly } \\
\text { on-peak } \\
\% \text { after } \\
\text { reduction }\end{array}$ \\
\hline 1 & 280 & 140 & 140 & 50 & 1.83 & $10 \%(14)$ & 126 & 45 & 1.64 \\
\hline 2 & 338 & 135 & 203 & 40 & 1.76 & $5 \%(7)$ & 128 & 38 & 1.67 \\
\hline 3 & 340 & 145 & 195 & 43 & 1.89 & $10 \%(15)$ & 130 & 38 & 1.7 \\
\hline 4 & 405 & 175 & 230 & 43 & 2.2 & $10 \%(18)$ & 157 & 39 & 2.05 \\
\hline 5 & 468 & 236 & 232 & 50 & 3.08 & $10 \%(24)$ & 212 & 45 & 2.77 \\
\hline 6 & 516 & 190 & 326 & 37 & 2.48 & $5 \%(10)$ & 180 & 35 & 2.35 \\
\hline 7 & 597 & 222 & 375 & 37 & 2.9 & $5 \%(11)$ & 211 & 35 & 2.75 \\
\hline 8 & 638 & 211 & 427 & 33 & 2.75 & $5 \%(11)$ & 200 & 31 & 2.61 \\
\hline 9 & 690 & 311 & 379 & 45 & 4.06 & $10 \%(31)$ & 280 & 41 & 3.66 \\
\hline 10 & 759 & 360 & 399 & 48 & 4.7 & $15 \%(54)$ & 306 & 40 & 4 \\
\hline 11 & 776 & 265 & 511 & 34 & 3.46 & $5 \%(14)$ & 251 & 32 & 3.28 \\
\hline 12 & 825 & 380 & 445 & 46 & 4.97 & $15 \%(57)$ & 323 & 39 & 4.22 \\
\hline 13 & 881 & 344 & 537 & 39 & 4.49 & $10 \%(35)$ & 309 & 35 & 4.04 \\
\hline 14 & 977 & 455 & 522 & 47 & 5.95 & $15 \div(68)$ & 387 & 40 & 5.06 \\
\hline 15 & 1011 & 423 & 588 & 42 & 5.53 & $10 \%(43)$ & 380 & 38 & 4.97 \\
\hline 16 & 1168 & 409 & 759 & 35 & 5.34 & $10 \%(41)$ & 368 & 31 & 4.81 \\
\hline 17 & 1322 & 575 & 747 & 44 & 7.52 & $15 \%(86)$ & 489 & 37 & 6.39 \\
\hline 18 & 1600 & 608 & 992 & 38 & 7.95 & $10 \%(61)$ & 547 & 34 & 7.15 \\
\hline 19 & 1838 & 844 & 994 & 46 & 11.03 & $15 \%(127)$ & 717 & 39 & 9.37 \\
\hline 20 & 2095 & 901 & 1194 & 43 & 11.7 & $15 \%(135)$ & 766 & 36 & 10.01 \\
\hline Total & 17524 & 7645 & & & & & 6467 & & \\
\hline
\end{tabular}

'Peak time consumption $\operatorname{limit}\left(\mathrm{P}_{\mathrm{L}}\right)$ ' column in table 3 gives estimated maximum units that are safe to consume during peak hours for each customer in such a way that they can shift to lower peak consumption clusters by consuming within the limit. Thus, with the proposed model, $15.4 \%$ of peak time consumption reduction per month can be achieved at utility level if the customers reach their individual goals. Customers too can attain good savings with this kind of target setting model especially when used along with TOU kind of tariffs.

A target report as shown in figure 5 can be sent to each customer at the beginning of the month based on the criteria shown in figure 3 . 


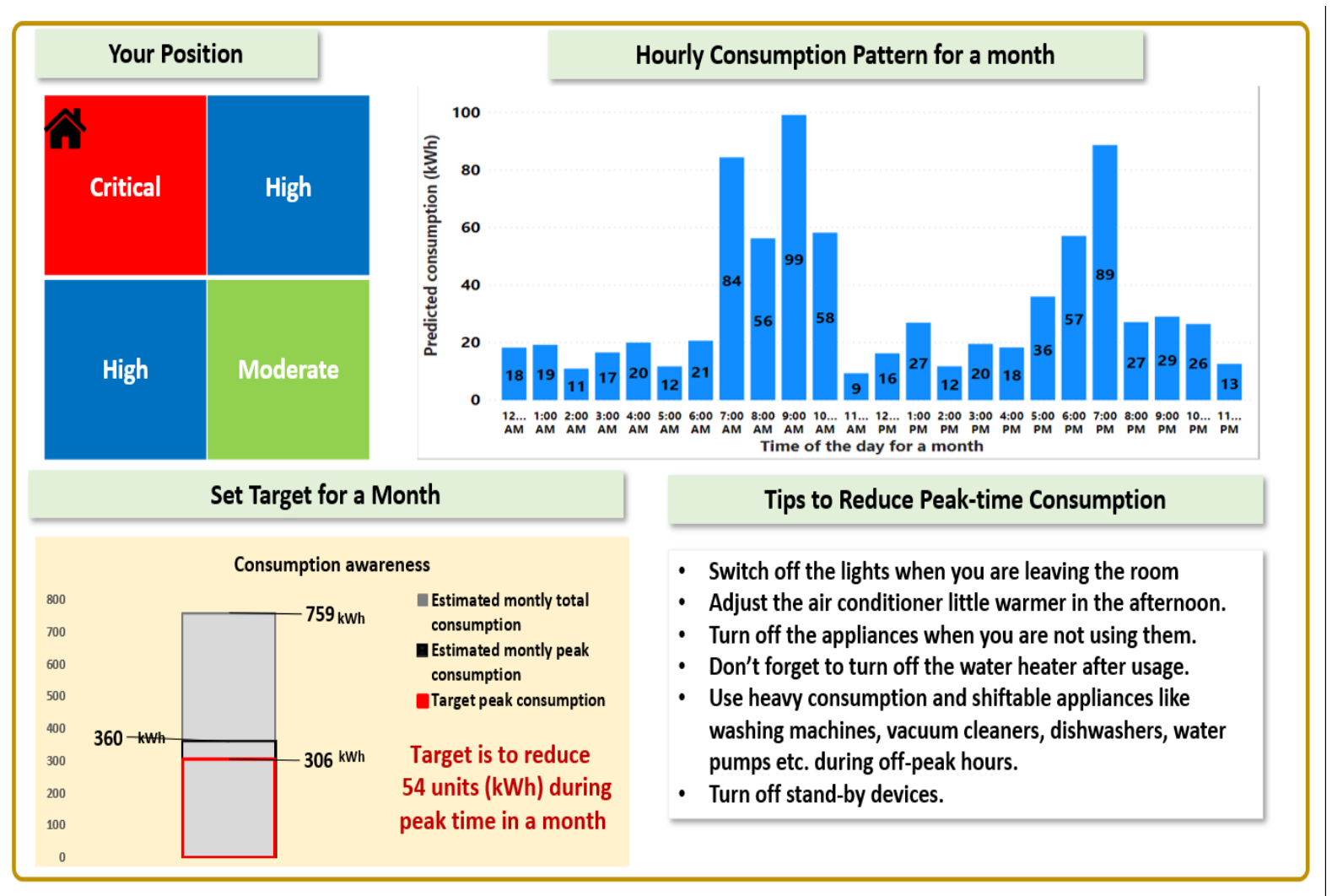

Fig 5: Target report based on forecasted monthly consumption

Thus, the individual target report gives below information to the customer:

- 'Your position' section shows customer's position compared to others in his/her community regarding peak time consumption for the coming month based on the criteria.

- 'Hourly consumption pattern for a month' section shows forecasted hourly consumption pattern of the customer for coming month which helps him/her to change their consumption style.

- 'Set target per month' section shows the estimated total monthly consumption, monthly peak time consumption, and safe peak time consumption limit for the coming month. Target in this section shows the estimated number of units to be reduced during peak hours in a month.

- 'Tips to reduce peak-time consumption' section gives the energy conservation tips for the customer.
Thus, from the report, it can be seen that $\mathrm{H}$. No:10 customer is a critical customer, with predicted monthly consumption of $759 \mathrm{kWh}$ and monthly peak time consumption of 360 $\mathrm{kWh}$ and hence a $10 \%$ reduction from the predicted peak time consumption is suggested to this customer. Peak time consumption limit $\left(\mathrm{P}_{\mathrm{L}}\right)$ is set to $306 \mathrm{kWh}$ and hence target is reduction of $54 \mathrm{kWh}$ consumption during peak hours.

\subsection{Proposed Feedback model:}

As mentioned earlier, a target along with feedback results in good savings rather than target alone. Feedback to customers with real time consumption information aids them to track their target achievement. Hence in this work, indirect weekly real-time feedback model for individual residential customer is proposed based on the goal/target set in the section 3.1. Figure 6 shows the proposed feedback model for individual customer. 


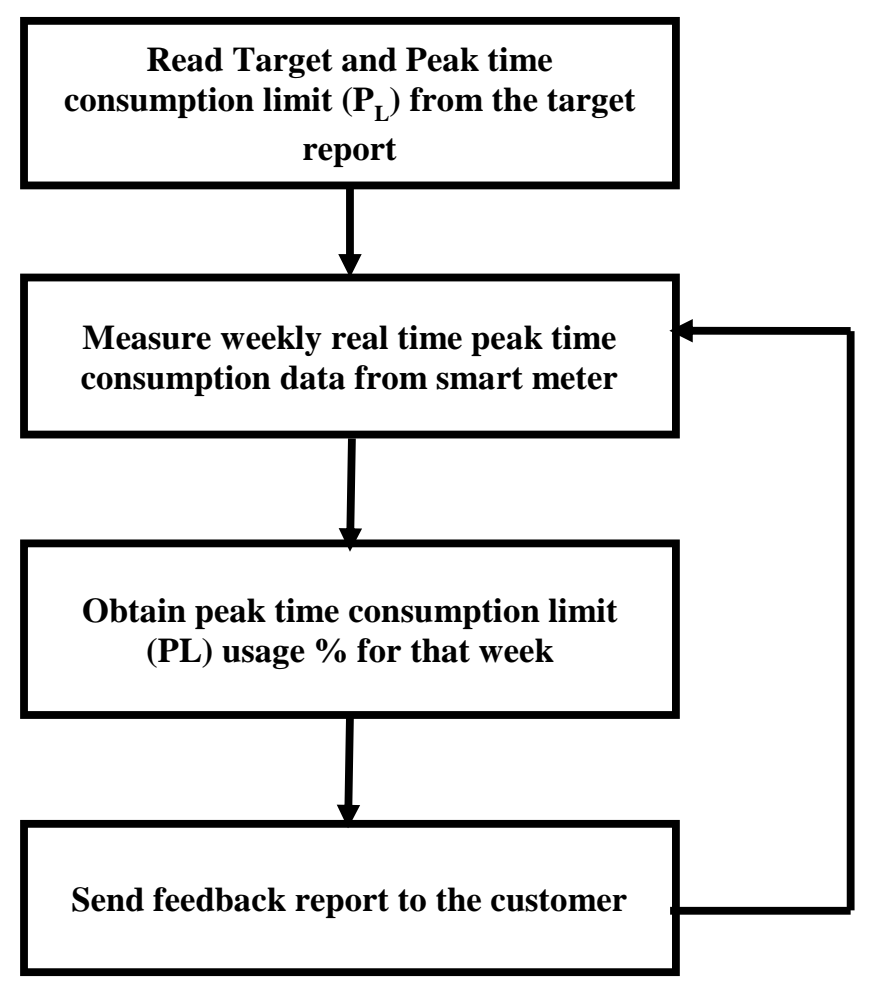

Fig 6: Feedback model cycle

Different stages of figure 6 are discussed below in detail:

1) Through target report, customer's estimated monthly Peak time consumption limit $\left(\mathrm{P}_{\mathrm{L}}\right)$ and estimated target of peak time consumption reduction is intimated to the customer at the beginning of the month based on the forecasted data.

Consider customer 10 who has monthly peak time consumption limit $\left(\mathrm{P}_{\mathrm{L}}\right)$ of $306 \mathrm{kWh}$, with monthly target to reduce $54 \mathrm{kWh}$ consumption during peak time.

2) Once the customer starts practicing the consumption changes to reach the target, first week real-time consumption data during peak hours is determined for the customer from smart meter.

Say real-time data from smart meter of customer10 during peak hours for week 1 is $50 \mathrm{kWh}$.

3) Peak time consumption limit Usage $\left(\mathrm{P}_{\mathrm{L}} \mathrm{U}\right) \%$ of the customer in that week 1 is obtained using equation (3). This gives the amount of energy or safe number of units left to be used during peak hours.

Thus, for customer 10, Peak time consumption limit Usage \% $\left(\mathrm{P}_{\mathrm{L}} \mathrm{U}\right) \%=70 / 306=23 \%$. He/she is still left with Peak time consumption Limit $\left(\mathrm{P}_{\mathrm{L}}\right)$ of $236 \mathrm{kWh}$.

4) A feedback report as shown in Figure 7 will be sent to the customer at the weekend regarding his $1^{\text {st }}$ week peak time usage out of his target and how many units of on-peak limit is he/she is still left with.

5) Similarly, based on the real-time data, second week consumption during peak hours is determined and Peak time consumption limit usage $\%\left(\mathrm{P}_{\mathrm{L}} \mathrm{U}\right) \%$ is obtained using equation (4).

6) A feedback will be sent to the customer regarding his $2^{\text {nd }}$ week usage out of his target and remaining Peak time consumption limit $\left(\mathrm{P}_{\mathrm{L}}\right)$.

7) Same can be repeated for every week.

Peak time consumption Limit Usage $\left(\mathrm{P}_{\mathrm{L}} \mathrm{U}\right) \%=\frac{(\text { Real-time week1 peak-time consumption })}{\text { Target }} \times 100$

Peak time consumption limit usage $\%,\left(\mathrm{P}_{\mathrm{L}} \mathrm{U}\right) \%=\frac{(\text { week1 peak time consumption }+ \text { week } 2 \text { peak time consumption })}{\text { Target }} \times 100$ 


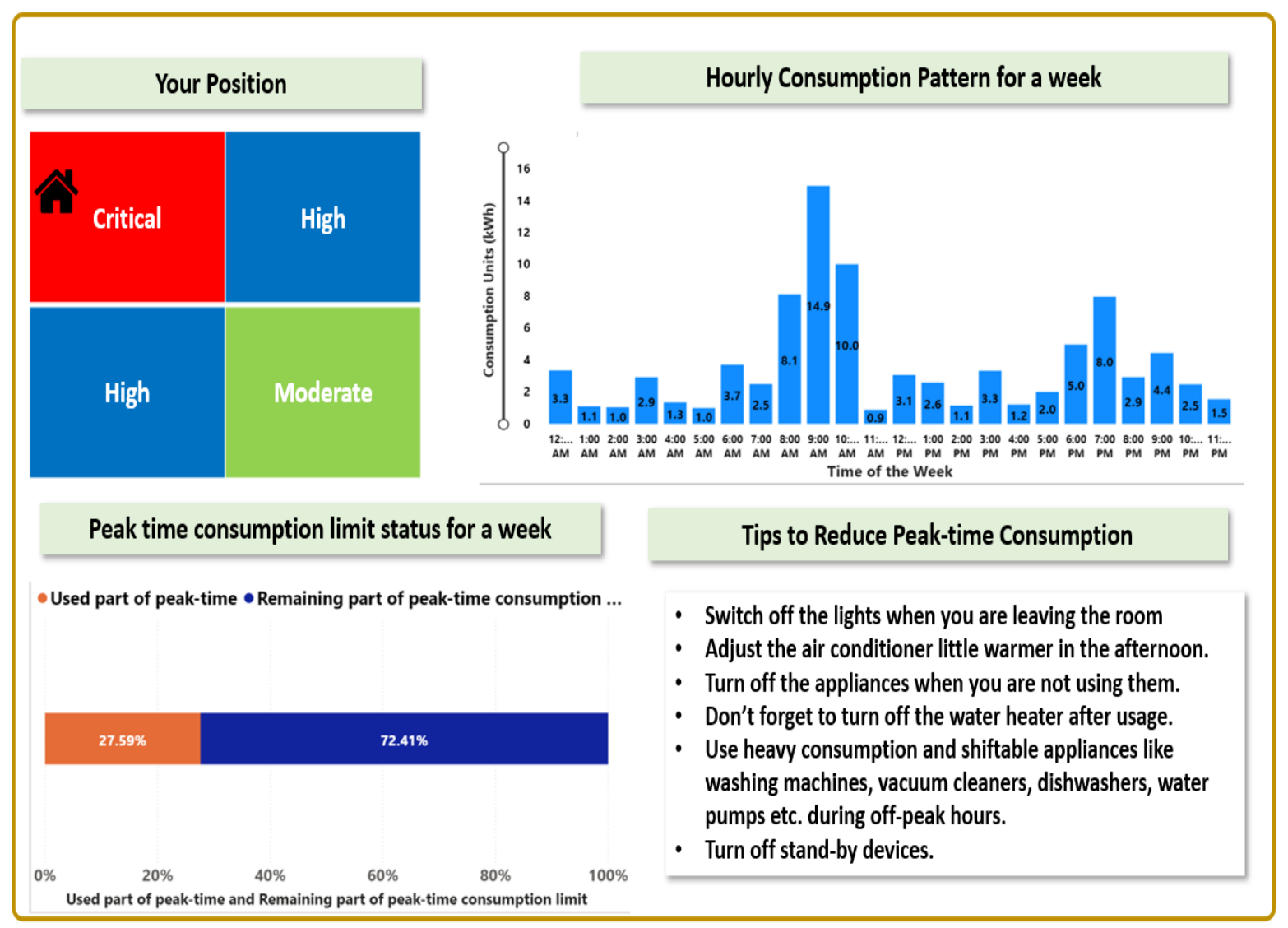

Fig 7: Feedback report based on set target and Real-time weekly consumption

A real-time weekly feedback report as in figure 7 consists of the following information:

- 'Your position' section shows the position of that particular house in terms of peak time consumption compared to other houses in that community for that particular week.

- 'Hourly consumption pattern for a week' section shows the real time weekly consumption pattern of that house on hourly basis based on real time data.

- 'Peak time consumption limit status for a week' section shows the units consumed out of peak time consumption limit till that week and the safe limit of units he/she is still left with.

- 'Tips to reduce peak-time consumption' section gives the energy conservation tips for the customer.

\section{Conclusion}

Personified Behavioural Demand Response model which comprises of individual target setting model and feedback model for reduction of domestic sector peak time energy consumption coincidence with utility peak time is proposed and implemented on synthetic smart meter data in this work. The model is so designed that each consumer is a set a goal of energy conservation or load shift between 5\%$15 \%$ during peak time based on the customer classification using k-means algorithm. This model helps in the reduction of domestic sector peak time energy consumption coincidence with utility without pressurizing or luring the customer and creating a burden on the utility. Though the results shown in this work are limited due to the application of the model on the synthetic smart meter data of India,

with 
with realistic data this model reaps great benefits to the utility and consumer without much requirements. On comparing the results of 20 individual houses with and without the model, proposed P-BDR model has shown a peak time energy consumption reduction of $14.9 \%$ without any technological installations and any incentives or pressures to the customer and the utility. The proposed work will be highly beneficial for developing countries like India, with plans to move towards smart grids and Demand Side Management (DSM) implementations.

\section{References:}

[1] M. Uddin et al.," A review on peak load shaving strategies", Renewable and Sustainable Energy Reviews, Vol.82, pp.3323-3332,2018.

[2] I. Khan, "Importance of GHG emissions assessment in the electricity grid expansion towards a low-carbon future: A time-varying carbon intensity approach", Journal of Cleaner Production, Vol.196, pp.1587-1599,2018.

[3] G.R. Newsham, B.G. Bowker, "The effect of utility time-varying pricing and load control strategies on residential summer peak electricity use: A review", Energy Policy, Vol.38, No.7,pp.3289-3296,2010.

[4] Bob Taylor, Colin Taylor," Demand Response: Managing electric power peak load shortages with market mechanisms", A Review of International Experience and Suggestions for China, by Regulatory Assistance Project(RAP), March 4,2015.

[5] Sarah Darby (2006)," The Effectiveness of Feedback on Energy Consumption",A Review for DEFRA of the Literature on Metering, Billing and direct Displays, https://www.eci.ox.ac.uk/research/energy/down loads/smart-metering-report.pdf.

[6] O.I. Asensio, M.A. Delmas," The dynamics of behavior change: Evidence from energy conservation", Vol.126, Part A, pp.196212,2016.

[7] Wikipedia contributors (2021, January 6)," Electricity sector in India, In Wikipedia, The Free Encyclopedia",
https://en.wikipedia.org/w/index.php?title=Ele ctricity_sector_in_India\&oldid=998634742.

[8] Central Electricity Authority," Optimal generation capacity mix for 2029-30",2019. https://cea.nic.in/old/reports/others/planning/irp /Optimal_generation_mix_report.pdf

[9] M.Z.Siddiqui, G. de Maere d'Aertrycke,Y. Smeers" Demand response in Indian electricity market",Energy Policy, Vol.50,pp. 207216,2012 .

[10] Ashok sarkar et.al ,Utility scale DSM opportunities and business models in India “, prepared for the World Bank energy and extractives global practice, South Asia Region,2016.

.http://documents.worldbank.org/curated/en/422 921488948129217/Utility-scale-DSMopportunities-and-business-models-in-Indiaprepared-for-the-WorldBank-energy-andextractives-global-practice-South-Asia-Region

[11] IEA , "India 2020", Energy policy review,2020.https://www.iea.org/reports/india2020

[12] Ahmad Faruqui et.al, "The power of 5 percent", The Electricity Journal,Vol.20,pp.6877,2007 .

[13] M. Mari (2007)," Affecting consumer behaviour on energy demand "Sussex Energy Group,(2007).

http://sro.sussex.ac.uk/id/eprint/21613

[14] Hunt Allocot, Todd Rogers," The short-run and long-run effects of behavioral interventions: experiment evidence from energy conservation",American Economic Review,Vol.104(10),pp.3003-3037,2014.

[15] S. Farshid, M.ParaS,K.Anurag Srivastava," Demand response for sustainable energy systems: A review, application and implementation strategy",Renewable and Sustainable Energy Reviews,Vol.45,pp.343350, 2015. 
[16] I. Khan," Energy-saving behaviour as a demand-side management strategy in the developing world: the case of Bangladesh", International Journal of Energy and En vironmental Engineering, Vol.10, pp.493510,2019 .

[17] Darby.S," The effectiveness of feedback on energy consumption", A Review for Defra of the literature on metering, billing and direct displays, by Environmental Change Institute, University of Oxford, April ,2006.

http://www.eci.ox.ac.uk/research/energy/downl oads/ smart-metering-report.pdf.

[18] L.T McCalley, Cees J.H Midden," Energy conservation through product-integrated feedback: the roles of goal-setting and social orientation", Journal of Economic Psychology, Vol.23(5),2002.

[19] Becker, L.J," Joint effect of feedback and goal setting on performance: a field study of residential energy conservation", Journal of Applied Psychology, Vol.63(4), pp.428-433, 1978.

[20] G. Kajal et.al.," Analysing the Electricity Demand Pattern" National Power Systems Conference (NPSC), Bhubaneswar, pp.16,2016 .

[21] S. Nathan et.al." An efficient k-means clustering algorithm: analysis and implementation", IEEE Transactions on Pattern Analysis and Machine Intelligence, Vol.24, pp.881-892,2002.

[22] Li, Youguo \& Wu, Haiyan. (2012). A Clustering Method Based on K-Means Algorithm. Physics Procedia. 25. 1104-1109. 10.1016/j.phpro.2012.03.206.

\section{Creative Commons Attribution License 4.0 (Attribution 4.0 International, CC BY 4.0)}

This article is published under the terms of the Creative Commons Attribution License 4.0

https://creativecommons.org/licenses/by/4.0/deed.en US 